\title{
High blood pressure, antihypertensive medication and lung function in a general adult population
}

\author{
Eva Schnabel ${ }^{1,2^{*}}$, Stefan Karrasch ${ }^{3,4,5}$, Holger Schulz ${ }^{1,3,5}$, Sven Gläser ${ }^{6}$, Christa Meisinger ${ }^{7,11}$, Margit Heier ${ }^{7,11}$, \\ Annette Peters ${ }^{8,11}$, H-Erich Wichmann ${ }^{1,8}$, Jürgen Behr ${ }^{5,9}$, Rudolf M Huber ${ }^{5,10}$ and Joachim Heinrich', for \\ for the Cooperative Health Research in the Region of Augsburg (KORA) Study Group
}

\begin{abstract}
Background: Several studies showed that blood pressure and lung function are associated. Additionally, a potential effect of antihypertensive medication, especially beta-blockers, on lung function has been discussed. However, side effects of beta-blockers have been investigated mainly in patients with already reduced lung function. Thus, aim of this analysis is to determine whether hypertension and antihypertensive medication have an adverse effect on lung function in a general adult population.
\end{abstract}

Methods: Within the population-based KORA F4 study 1319 adults aged 40-65 years performed lung function tests and blood pressure measurements. Additionally, information on anthropometric measurements, medical history and use of antihypertensive medication was available. Multivariable regression models were applied to study the association between blood pressure, antihypertensive medication and lung function.

Results: High blood pressure as well as antihypertensive medication were associated with lower forced expiratory volume in one second $\left(p=0.02\right.$ respectively $\left.p=0.05 ; R^{2}: 0.65\right)$ and forced vital capacity values $(p=0.01$ respectively $p=0.05, R^{2}: 0.73$ ). Furthermore, a detailed analysis of antihypertensive medication pointed out that only the use of beta-blockers was associated with reduced lung function, whereas other antihypertensive medication had no effect on lung function. The adverse effect of beta-blockers was significant for forced vital capacity ( $p=0.04 ; R^{2}: 0.65$ ), while the association with forced expiratory volume in one second showed a trend toward significance $\left(p=0.07 ; R^{2}: 0.73\right)$. In the same model high blood pressure was associated with reduced forced vital capacity $(p=0.01)$ and forced expiratory volume in one second $(p=0.03)$ values, too.

Conclusion: Our analysis indicates that both high blood pressure and the use of beta-blockers, but not the use of other antihypertensive medication, are associated with reduced lung function in a general adult population.

\section{Background}

Hypertension is an increasingly important public health challenge worldwide and it is one of the major causes for morbidity and mortality [1]. Thus, the National High Blood Pressure Education Program reports that the global burden of hypertension is approximately 1 billion individuals and that more than 7 million deaths per year may be attributable to hypertension [2].

Moreover, hypertension has been linked to multiple other diseases including cardiac, cerebrovascular, renal

\footnotetext{
* Correspondence: Schnabel@helmholtz-muenchen.de ${ }^{1}$ Helmholtz Zentrum München, German Research Center for Environmental Health, Institute of Epidemiology, Neuherberg, Germany Full list of author information is available at the end of the article
}

and eye diseases [3]. Beside the well-established association between hypertension and vascular comorbidities, several studies showed that blood pressure and lung function are associated [4-9]. It could be demonstrated that higher forced vital capacity (FVC) is a negative predictor of developing hypertension $[7,8]$. Moreover, some studies found an association between reduced pulmonary function, including both low FVC and low forced expiratory volume in one second $\left(\mathrm{FEV}_{1}\right)$, and hypertension $[5,9,6]$.

Furthermore, there are a number of publications discussing the controversial effect of beta-blockers (BBL) on lung function [10-16]. It is well established that BBL, even relatively cardioselective agents, can produce bronchoconstriction and thereby worsen respiratory
C Biomed Central 
flows and symptoms in patients with asthma or chronic obstructive pulmonary disease (COPD) $[10,16,12]$. However, two recent studies suggested that the treatment of cardiovascular diseases with cardioselective BBL, may reduce morbidity and mortality in patients with COPD $[11,15]$. Two systematic reviews of randomized controlled trials showed that the use of cardioselective BBL in patients with asthma or COPD has no adverse effects on lung function or respiratory symptoms [13,14]. However, these studies investigated the potential effect of BBL intake on lung function mainly in patients with already existing pulmonary diseases. The association between blood pressure, antihypertensive drug treatment and limited lung function in a population-based setting is much less investigated. Thus, the aim of this analysis is to determine whether hypertension as well as antihypertensive medication has an adverse effect on lung function in a general adult population.

\section{Methods}

\section{Study population}

The KORA F4 study is a follow-up of the KORA S4 study, a population-based health survey conducted in the city of Augsburg and two surrounding counties between 1999 and 2001. A total sample of 6640 subjects was drawn from the target population consisting of all German residents of the region aged 25 to 74 years.

Of all 4261 participants of the S4 baseline study, 3080 also participated in the 7-year follow-up F4 study. Persons were considered ineligible for F4 if they had died in the meantime ( $\mathrm{n}=176,4 \%)$, lived outside the study region or were completely lost to follow-up $(n=206$, $5 \%)$, or had demanded deletion of their address data $(\mathrm{n}=$ $12,0.2 \%)$. Of the remaining 3867 eligible persons, 174 could not be contacted, 218 were unable to come because they were too ill or had no time, and 395 were not willing to participate in this follow-up, giving a response rate of $79.6 \%$. Our study focuses on a subset of 1319 persons aged 40-65 years, because only this age-restricted subset performed both blood pressure measurements and lung function tests. The clinical examinations and interviews were performed at the same day. Overall, the KORA F4 study was conducted between 2006 and 2008.

The investigations were carried out in accordance with the Declaration of Helsinki, including written informed consent of all participants. All study methods were approved by the ethics committee of the Bavarian Chamber of Physicians, Munich.

\section{Outcome assessment \\ Lung function}

Lung function examinations, i.e. spirometry, were conducted based on the American Thoracic Society (ATS) criteria [17] and the recommendations of the European
Community for Steel and Coal (ECCS) [18]. The participants performed at least three forced expiratory lung function manoeuvres in order to obtain a minimum of two acceptable and reproducible values. Before the tests the examiner demonstrated the correct performance of the manoeuvres and then the individuals were supervised throughout the tests. According to the ATS recommendations [17] the tests were performed in a sitting position and with wearing noseclips. The best results for $\mathrm{FVC}$ and $\mathrm{FEV}_{1}$ were taken and percent predicted values were calculated according Quanjer et al. [18].

\section{Blood pressure, medication and other determinats}

Blood pressure was measured using a validated automatic device (OMRON HEM 705-CP). Three independent blood pressure measurements were taken with a 3-minute pause after a rest of at least 5 minutes in a sitting position on the right arm. The mean of the last two measurements was used for the current analyses. High blood pressure (HBP) was defined as blood pressure $\geq 140 \mathrm{~mm} \mathrm{Hg}$ systolic or $90 \mathrm{~mm} \mathrm{Hg}$ diastolic (with or without antihypertensive medications). Additionally, anthropometric measurements, computer-assisted standardized interviews and selfadministered questionnaires on lifestyle and health related factors, medical history and respiratory symptoms were performed. Cardiovascular (heart attack, stroke) and pulmonary diseases (asthma, chronic bronchitis) were based on self-reported physician's diagnosis. The smoking status (current, former, or never-smokers) was assessed by selfreport. Education level was defined by the highest graduation (less than O-level, O-level and more than O-level). Furthermore, the use of medication within the last seven days before the examination was ascertained by an instrument for database-assisted online collection of medication data (IDOM) [19]. The following substance classes were considered as antihypertensive medication according to the recommendations of the German Hypertension Association [20]: Antihypertensives (ATC code C02), diuretics (ATC code C03), beta-blocker (ATC code C07), calcium antagonists (ATC code C08), ACE inhibitors and angiotensin antagonists (ATC code C09). Finally, the following classes of high blood pressure based on the blood pressure measurement (HBP $\geq 140 / 90 \mathrm{mmHg}$ ) and antihypertensive medication were defined:

- A. HBP: high blood pressure regardless of its medical treatment

- B. HBP or medication: high blood pressure or the use of antihypertensive medication

- C. HBP and medication: high blood pressure and the use of antihypertensive medication; treated but uncontrolled hypertension

- D. Only HBP: high blood pressure, but no antihypertensive medication; untreated hypertension 
- E. Only medication for HBP: antihypertensive medication, but no high blood pressure; treated and controlled hypertension

- F. Medication for HBP: antihypertensive medication independent of high blood pressure

\section{Statistical analyses}

Descriptive analysis for the study population, blood pressure and lung function measures was done using chisquare and Kruskal Wallis tests to determine significance levels. Kruskal-Wallis tests and multivariable linear regression models were applied to study the association between the abovementioned classes of high blood pressure and antihypertensive medication and lung function outcomes. Additionally, high blood pressure and antihypertensive medication were used as individual variables in one regression model. P-values $<0.05$ were considered statistically significant for all analyses. All statistical analysis was performed with SAS, version 9.13.

\section{Results}

Table 1 shows gender-specific characteristics of the 1319 participants with complete data on lung function tests and blood pressure measurements. Women had a significantly lower body mass index (BMI), smoked less and their blood pressure readings and absolute lung function values were lower, whereas their percent predicted lung function values were higher compared to men ( $\mathrm{p}<0.01$ for each comparison). Overall high blood pressure was less prevalent in women compared to men (10.3\% versus 23.1\%; $\mathrm{p}<0.01$ ). However, for the use of antihypertensive medication there was no difference between women and men.

In subjects with high blood pressure $\mathrm{FEV}_{1} \%$ predicted $(105.8 \pm 16.0$ versus $109.3 \pm 16.9 ; \mathrm{p}<0.01)$ and FVC \% predicted $(111.6 \pm 14.8$ versus $117.0 \pm 15.5 ; \mathrm{p}<0.01)$ were significant lower (Table 2). A similar significant difference of $\mathrm{FEV}_{1} \%$ predicted $(105.4 \pm 16.4$ versus $109.5 \pm 16.8 ; \mathrm{p}<$ $0.01)$ and of FVC \% predicted (111.9 \pm 16.1 versus $117.1 \pm$ $15.3 ; \mathrm{p}<0.01)$ could be shown for the use of antihypertensive medication irrespective of high blood pressure. Furthermore, an effective blood pressure treatment and an ineffective blood pressure treatment, meaning high blood pressure despite the use of antihypertensive medication, were associated with lower $\mathrm{FEV}_{1} \%(\mathrm{p}=0.04$ and $\mathrm{p}<0.01$, respectively) and FVC \% predicted values ( $\mathrm{p}=0.01$ and $\mathrm{p}<0.01$, respectively)

Similar results for the association between high blood pressure, antihypertensive medication and lung function could be shown in men. In women $\mathrm{FEV}_{1}$ and $\mathrm{FVC} \%$ predicted values did not differ between subjects with and without high blood pressure. However, the use of antihypertensive medication irrespective of high blood pressure was associated with a significant reduced $\mathrm{FEV}_{1}$ and FVC \% values in women $(\mathrm{p}=0.02$ and $\mathrm{p}<0.01$, respectively).

The descriptive analysis (Table 2) of the association between lung function and antihypertensive medication showed that both BBL and other antihypertensive medication, as for example ACE inhibitors, angiotensin antagonists, diuretics or calcium antagonist, are associated with reduced $\mathrm{FEV}_{1}$ and $\mathrm{FVC} \%$ predicted values ( $\mathrm{p}=0.01$ and $\mathrm{p}<0.01$, respectively)

The application of multivariable regression models revealed that high blood pressure as well as antihypertensive medication are associated with lower $\mathrm{FEV}_{1}(\mathrm{p}=0.02$ and $\mathrm{p}=0.05$, respectively) and FVC values $(\mathrm{p}=0.01$ and $\mathrm{p}=0.05$, respectively) after adjusting for sex, age, height, weight, education level, packyears of smoking, pulmonary and cardiac diseases (Table 3, Model 1 and 3). When using both high blood pressure and antihypertensive medication as individual variables in one regression model, it could be shown, that both variables were associated with reduced lung function values (Model 6). However, antihypertensive medication showed only a trend toward a significant association with lower $\mathrm{FEV}_{1}$ and FVC values (each $\mathrm{p}=0.08$ ). Furthermore, the adjusted regression models with mutual exclusive categories pointed out that the combination of high blood pressure and the use of antihypertensive medication had the strongest negative effect on lung function (Model 4). Thus, among treated but not controlled hypertensive subjects $\mathrm{FEV}_{1}$ had a lower volume of $160 \mathrm{~mL}$ and FVC of $170 \mathrm{~mL}$ compared to subjects with no high blood pressure and no antihypertensive medication (each $\mathrm{p}=0.02$ and $\mathrm{p}=0.02$ ). A detailed analysis of antihypertensive medication showed that the use of BBL was associated with reduced $\mathrm{FEV}_{1}$ and $\mathrm{FVC}$ values, whereas other antihypertensive medication had no effect on lung function (Model 5). However, it has to be considered that the effect of BBL was significant for FVC ( $p=0.03$ ) while for $\mathrm{FEV}_{1}$ the association was of borderline significance $(\mathrm{p}=$ 0.07). A further model including BBL, other antihypertensive medication and high blood pressure showed similar negative effects of BBL on FVC ( $p=0.04$ ) and $\mathrm{FEV}_{1}$ $(\mathrm{p}=0.07)$. Besides, high blood pressure was associated with reduced FVC $(\mathrm{p}=0.01)$ and $\mathrm{FEV}_{1}(\mathrm{p}=0.03)$ values, too (Model 5a). An additional sensitivity analysis of the models 5 and 6 , where we excluded subjects with obstructive lung diseases, showed that the effect of BBL still exists. Although the significance level declined the magnitude effect estimates did not change. For all multivariable regression models the adjusted $r$-squared value was 0.65 for $\mathrm{FEV}_{1}$ and 0.73 for FVC.

A further sensitivity analysis regarding the possible effect modification by gender showed no gender difference for $\mathrm{FEV}_{1}$ for all models. The multivariable regression models for FVC, however, showed a significant interaction 
Table 1 Characteristics of the study population based on KORA F4, persons aged 40-65 years with blood pressure measurements and lung function tests

\begin{tabular}{|c|c|c|c|}
\hline & $\begin{array}{c}\text { Men }(\mathrm{N}=618) \\
\text { Mean } \pm \mathrm{SD}\end{array}$ & $\begin{array}{c}\text { Women }(\mathrm{N}=701) \\
\text { Mean } \pm \mathrm{SD}\end{array}$ & P-Value \\
\hline Age (years) & $51.6 \pm 5.8$ & $51.5 \pm 5.6$ & 0.83 \\
\hline BMI $\left(\mathrm{kg} / \mathrm{m}^{2}\right)$ & $28.0 \pm 4.5$ & $26.9 \pm 5.2$ & $<0.01$ \\
\hline Packyears (y) & $21.8 \pm 20.1$ & $13.4 \pm 12.9$ & $<0.01$ \\
\hline \multicolumn{4}{|l|}{ Blood pressure } \\
\hline Mean SBP $(\mathrm{mm} \mathrm{Hg})$ & $126.3 \pm 16.1$ & $114.9 \pm 15.8$ & $<0.01$ \\
\hline Mean DBP (mm Hg) & $80.1 \pm 9.8$ & $74.1 \pm 9.0$ & $<0.01$ \\
\hline \multicolumn{4}{|l|}{ Lung function } \\
\hline $\mathrm{FEV}_{1}(\mathrm{I})$ & $3.9 \pm 0.7$ & $2.8 \pm 0.5$ & $<0.01$ \\
\hline FVC (I) & $5.0 \pm 0.8$ & $3.6 \pm 0.6$ & $<0.01$ \\
\hline $\mathrm{FEV}_{1} \%$ predicted $^{\mathbf{S}}$ & $107.2 \pm 16.2$ & $110.1 \pm 17.2$ & $<0.01$ \\
\hline \multirow[t]{2}{*}{ FVC \% predicted $\$$} & $111.5 \pm 13.7$ & $120.2 \pm 16.0$ & $<0.01$ \\
\hline & n (\%) & n (\%) & P-Value \\
\hline \multicolumn{4}{|l|}{ Pulmonary and cardiac diseases } \\
\hline Asthma & $50(8.1)$ & $69(9.8)$ & 0.27 \\
\hline Chronic bronchitis & $49(8.0)$ & $58(8.3)$ & 0.81 \\
\hline Heart attack & $17(2.8)$ & $11(1.6)$ & 0.14 \\
\hline Stroke & $15(2.4)$ & $2(0.3)$ & $<0.01$ \\
\hline \multicolumn{4}{|l|}{ Smoking status } \\
\hline current & $155(25.1)$ & $150(21.4)$ & 0.11 \\
\hline former & $268(43.4)$ & $236(33.7)$ & $<0.01$ \\
\hline never & $195(31.6)$ & $315(45.0)$ & $<0.01$ \\
\hline \multicolumn{4}{|c|}{ High blood pressure and medication*classes } \\
\hline $\mathrm{HBP}$ & $143(23.1)$ & $72(10.3)$ & $<0.01$ \\
\hline HBP or medication* & $221(35.8)$ & $177(25.3)$ & $<0.01$ \\
\hline HBP and medication* & $46(7.4)$ & $22(3.1)$ & $<0.01$ \\
\hline Only HBP & $97(15.7)$ & $50(7.1)$ & $<0.01$ \\
\hline Only medication*for HBP & $78(12.6)$ & $105(15.0)$ & 0.22 \\
\hline Medication* for HBP & $124(20.1)$ & $127(18.1)$ & 0.37 \\
\hline Beta-blocker & $68(11.4)$ & $82(11.8)$ & 0.67 \\
\hline ACE inhibitor & $52(8.4)$ & $44(6.3)$ & 0.14 \\
\hline Angiotensin antagonists & $41(6.6)$ & $33(4.7)$ & 0.13 \\
\hline Diuretics & $63(10.2)$ & $60(8.6)$ & 0.32 \\
\hline Calcium antagonists & $25(4.1)$ & $25(3.6)$ & 0.65 \\
\hline Other antihypertensive drugs & $3(0.5)$ & $4(0.6)$ & 0.83 \\
\hline
\end{tabular}

SBP: systolic blood pressure; DBP: diastolic blood pressure; HBP: high blood pressure.

$\left(\geq 140 / 90 \mathrm{mmHg}\right.$ ); $\mathrm{FEV}_{1}$ : forced expiratory volume in one second; FVC: forced vital capacity.

*Medication: antihypertensive medication; ${ }^{\$} \%$ predicted values according to Quanjer; ${ }^{*}$ Obtained from the chi-square test when comparing frequencies and from the Kruskal Wallis test when comparing mean values.

between gender and high blood pressure, indicating that high blood pressure has a lower effect on lung function in women compared to men. Further analyses regarding the ratio $\mathrm{FEV}_{1} / \mathrm{FVC}$ showed no significant association between high blood pressure or antihypertensive medication and the ratio $\mathrm{FEV}_{1} / \mathrm{FVC}$.

\section{Discussion}

The present analysis of a population-based study demonstrates that both high blood pressure and the use of $\mathrm{BBL}$ are associated with reduced lung function, whereas other antihypertensive medications have no effect on lung function.

Our findings are in line with previous observations that blood pressure and lung function are inversely associated $[5,6,9]$. But most of these studies did not differentiate between the effect of high blood pressure and the effect of antihypertensive medication on lung function. Instead they defined hypertension as elevated blood pressure or use of antihypertensive medication. One study, however, found no difference in $\mathrm{FEV}_{1}$ and FVC between hypertensive subjects that used or did not use beta blocking 
Table 2 Crude association between high blood pressure, antihypertensive medication and lung function

\begin{tabular}{|c|c|c|c|c|c|}
\hline & $\mathrm{N}$ & $\mathrm{FEV}_{1} \%^{\$}$ & P-Value $^{\#}$ & FVC $\%^{\$}$ & P-Value \\
\hline \multicolumn{6}{|l|}{ HBP } \\
\hline Yes & 215 & $105.8 \pm 16.0$ & $<0.01$ & $111.6 \pm 14.8$ & $<0.01$ \\
\hline No & 1104 & $109.3 \pm 16.9$ & & $117.0 \pm 15.5$ & \\
\hline \multicolumn{6}{|l|}{ HBP or medication* } \\
\hline Yes & 398 & $106.0 \pm 16.3$ & $<0.01$ & $112.3 \pm 15.4$ & $<0.01$ \\
\hline No & 921 & $109.9 \pm 16.9$ & & $117.8 \pm 15.3$ & \\
\hline \multicolumn{6}{|l|}{ HBP and medication* } \\
\hline Yes & 68 & $103.1 \pm 15.7$ & $<0.01$ & $108.5 \pm 15.8$ & $<0.01$ \\
\hline No & 1251 & $109.1 \pm 16.8$ & & $116.6 \pm 15.4$ & \\
\hline \multicolumn{6}{|l|}{ Only HBP } \\
\hline Yes & 147 & $107.0 \pm 16.0$ & 0.19 & $112.9 \pm 14.2$ & 0.01 \\
\hline No & 1172 & $109.0 \pm 16.9$ & & $116.5 \pm 15.7$ & \\
\hline \multicolumn{6}{|l|}{ Only medication* for HBP } \\
\hline Yes & 183 & $106.3 \pm 16.7$ & 0.04 & $113.2 \pm 16.0$ & 0.01 \\
\hline No & 1136 & $109.2 \pm 16.8$ & & $116.6 \pm 15.4$ & \\
\hline \multicolumn{6}{|l|}{ Medication* for HBP } \\
\hline Yes & 251 & $105.4 \pm 16.4$ & $<0.01$ & $111.9 \pm 16.1$ & $<0.01$ \\
\hline No & 1068 & $109.5 \pm 16.8$ & & $117.1 \pm 15.3$ & \\
\hline \multicolumn{6}{|l|}{ Medication* for HBP } \\
\hline Beta-blocker & 150 & $105.8 \pm 16.1$ & 0.01 & $112.0 \pm 15.7$ & $<0.01$ \\
\hline Other antihypertensive drugs & 101 & $104.9 \pm 16.9$ & 0.01 & $111.7 \pm 16.7$ & $<0.01$ \\
\hline No antihypertensive drugs & 1068 & $109.5 \pm 16.8$ & & $117.1 \pm 15.3$ & \\
\hline
\end{tabular}

HBP: high blood pressure ( $\geq 140 / 90 \mathrm{mmHg}$ ); $\mathrm{FEV}_{1}$ : forced expiratory volume in one second; FVC: forced vital capacity; ${ }^{*}$ Medication: antihypertensive medication; \$ predicted values according to Quanjer: mean \pm standard deviation; ${ }^{\#}$ Obtained from Kruskal Wallis Test.

antihypertensives [6], but they did not specifically address the effect of antihypertensive medication independent of high blood pressure on lung function.

Thus, our study might substantially add to the question, whether antihypertensive BBL medication independent of high blood pressure has adverse effects on lung function. Beta-adrenergic receptors ( $\beta$-ARs) play a key role in the regulation of bronchomotor tone [21]. In the respiratory system most of the $\beta$-ARs are $\beta 2$-ARs. However, there are $\beta 1$-ARs, too, which are responsible for the respiratory effects of cardioselective $\beta 1$-antagonists. Two systematic reviews suggest that cardioselective BBL do not produce adverse respiratory effects in patients with asthma or COPD $[13,14]$. These randomized clinical trials examined only patients with already existing pulmonary diseases and not healthy subjects. Other studies provide evidence that BBL medication, even relatively cardioselective agents, produce bronchoconstriction and thereby worsen respiratory flows in asthmatic patients $[10,16]$. Our results indicate that the use of BBL medication is associated with a slight reduction of $\mathrm{FEV}_{1}$ and FVC. Interestingly, the $\mathrm{FEV}_{1}$ / FVC ratio was found not to be affected by BBL medication suggesting that the expired volume, FVC, is lowered in proportion. Indeed, the drug-specific effect of BBL medication is more pronounced on FVC than on $\mathrm{FEV}_{1}$. This supports the hypothesis that not airway obstruction, but rather restriction is the more likely mechanism involved in the effect of BBL medication on lung function. For instance, possible effects on the respiratory muscle strength have to be considered. It is well established that beta agonists improve the performance of skeletal muscles [22] and also positively affect respiratory muscle strength $[23,24]$. The opposite effect by BBL medication is suggested by a recent study from Frankenstein et al. performed in patients with chronic heart failure [25]. Thus, we hypothesize that BBL medication may result in a slight reduction of expiratory muscle strength causing a proportional decrease of $\mathrm{FEV}_{1}$ and FVC. However, further studies directly addressing this issue are required.

When reviewing our results, it becomes apparent that from a statistical point of view both high blood pressure and antihypertensive BBL medication have an effect on lung function measurements. But the observed lung function differences between exposed und non-exposed subjects are relatively small, meaning that they have no direct clinical consequence in healthy individuals. However, we could show that among treated but not controlled hypertensive subjects $\mathrm{FEV}_{1}$ had a lower volume of $160 \mathrm{~mL}$ compared to subjects with no high blood pressure and no antihypertensive medication. This finding might be of importance on the population level. One possible explanation for this significant lung function reduction might be 
Table 3 Association between high blood pressure, antihypertensive medication and lung function - results of the multivariable regression analysis

\begin{tabular}{|c|c|c|c|c|c|c|c|c|}
\hline \multicolumn{5}{|c|}{ Models for FEV (L) $_{1}$} & \multicolumn{4}{|l|}{ Models for FVC (L) } \\
\hline Nr. & Variable & Estimate & SD & $P^{\#}$ & Variable & Estimate & SD & $P^{\#}$ \\
\hline & \multicolumn{4}{|c|}{ HBP and antihypertensive medication classes } & \multicolumn{4}{|c|}{ HBP and antihypertensive medication classes } \\
\hline 1. & $\mathrm{HBP}$ & -0.09 & 0.04 & 0.02 & $\mathrm{HBP}$ & -0.11 & 0.04 & 0.01 \\
\hline 2. & HBP or medication & -0.08 & 0.03 & 0.01 & HBP or medication & -0.10 & 0.03 & $<0.01$ \\
\hline \multirow[t]{2}{*}{3.} & Medication & -0.07 & 0.04 & 0.05 & Medication & -0.08 & 0.04 & 0.05 \\
\hline & \multicolumn{4}{|c|}{ Models with mutual exclusive categories } & \multicolumn{4}{|c|}{ Models with mutual exclusive categories } \\
\hline \multirow[t]{4}{*}{4.} & No HBP, no medication ${ }^{\S}$ & & & & No HBP, no medication ${ }^{\S}$ & & & \\
\hline & HBP and medication & -0.16 & 0.06 & 0.02 & HBP and medication & -0.17 & 0.07 & 0.02 \\
\hline & Only HBP & -0.08 & 0.04 & 0.09 & Only HBP & -0.10 & 0.05 & 0.04 \\
\hline & Only medication & -0.06 & 0.04 & 0.14 & Only medication & -0.07 & 0.05 & 0.12 \\
\hline \multirow[t]{3}{*}{5.} & No anti-hypertensive drugs ${ }^{\S}$ & & & & No anti-hypertensive drugs $s^{\S}$ & & & \\
\hline & Beta blocker & -0.08 & 0.05 & 0.07 & Beta blocker & -0.11 & 0.05 & 0.03 \\
\hline & Other anti-hypertensive drugs & -0.06 & 0.05 & 0.28 & Other anti-hypertensive drugs & -0.04 & 0.06 & 0.51 \\
\hline \multirow[t]{5}{*}{$5 a}$. & No anti-hypertensive drugs ${ }^{\S}$ & & & & No anti-hypertensive drugs $s^{\S}$ & & & \\
\hline & Beta blocker & -0.08 & 0.05 & 0.07 & Beta blocker & -0.10 & 0.05 & 0.04 \\
\hline & Other anti-hypertensive drugs & -0.04 & 0.05 & 0.41 & Other anti-hypertensive drugs & -0.02 & 0.06 & 0.72 \\
\hline & $\mathrm{HBP}$ & -0.08 & 0.04 & 0.03 & $\mathrm{HBP}$ & -0.10 & 0.04 & 0.01 \\
\hline & \multicolumn{4}{|c|}{ HBP and antihypertensive medication as individual variables } & \multicolumn{4}{|c|}{$\mathrm{HBP}$ and antihypertensive medication as individual variables } \\
\hline \multirow[t]{2}{*}{6.} & $\mathrm{HBP}$ & -0.08 & 0.04 & 0.03 & $\mathrm{HBP}$ & -0.10 & 0.04 & 0.02 \\
\hline & Medication & -0.07 & 0.04 & 0.08 & Medication & -0.07 & 0.04 & 0.08 \\
\hline
\end{tabular}

Multivariable regression analysis using the high blood pressure and antihypertensive medication classes (Model 1-3), mutual exclusive categories (Model 4,5,5a) and high blood pressure and antihypertensive medication as individual variables (Model 6).

SD: standard deviation; $\mathrm{FEV}_{1}$ : forced expiratory volume in one second; FVC: forced vital capacity; HBP: high blood pressure ( $\geq 140 / 90$ mmHg); Medication: antihypertensive medication; ${ }^{\S}$ Reference category; ${ }^{\#}$ P-Value: all models are adjusted for gender, age, height, weight, education level, packyears, pulmonary and cardiac diseases.

an additive effect of both treatment and persistent high blood pressure. However, the cross-sectional study design makes it difficult to disentangle the effects of high blood pressure and antihypertensive medication. Thus, it allows only statements about a single point in time and does not allow evaluating the effect of long-standing high blood pressure. Another explanation for this lung function decrement could be that those with persistent hypertension despite medical treatment have a higher underlying blood pressure compared to effectively treated subject. Moreover, the effects of high blood pressure and antihypertensive medication are highly correlated. A detailed analysis of antihypertensive medication indicates that BBL medication and not any other antihypertensive medication is associated with a reduced lung function. This negative effect of BBL medication still remains, when BBL, other antihypertensive medication and high blood pressure are analysed in the same model. Besides, BBL are the most common prescribed antihypertensive medication and it has to be considered that BBL medication might be prescribed for other indications than hypertension, as for example, coronary heart diseases or heart failure, too. This again suggests that the effect of antihypertensive BBL medication on lung function is mainly ascribed to the medicament and not to the indication. Furthermore, a variety of confounders might affect the association between high blood pressure, antihypertensive medication and lung function. Cigarette smoking is a common risk factor for both impaired lung function and high blood pressure and BMI might have an effect on lung function. However, adjustment for these possible confounders did not influence our results. Moreover, we could show that the association was not affected by the concomitance of pulmonary diseases and that the negative effect of BBL medication on lung function is not modified by obstructive lung diseases. This supports our interpretation that BBL have an effect on lung function in the general population. Besides, our results suggest that there may be an effect modification by gender. We could show that in women the percent predicted lung function values did not differ between subjects with and without high blood pressure. Furthermore, the multivariable regression analysis revealed a significant interaction between gender and high blood pressure. This might possibly indicate that high blood pressure has minor effect on lung function in women compared to men.

The large sample size and the population-based setting are a major strength of this study. Furthermore, it is one of few investigations differentiating between the effect of blood pressure and antihypertensive drug 
treatment on lung function. Nevertheless, this study has some possible limitation. Methodological bias might lead to insufficient lung function measurements. Thus in patients with high blood pressure lung function tests might be stopped earlier, because the respiratory effort might cause an increase in blood pressure. However, we consider this possible bias unlikely to affect our findings. Besides, selection bias might limit the representative status of the population sample included in our analysis. We had to restrict our analysis to subjects aged 40-65 years, because only this age-restricted subset performed lung function tests. However, as this was a random sample, we consider that our population sample is highly representative for this age group of the Augsburg population. Moreover, the cross-sectional study design makes it difficult to make a clear statement about the temporal sequence and causality between high blood pressure, its treatment and lung function. Several prospective studies indicated that high blood pressure is a risk factor for reduced lung function as well as impaired lung function increases the risk for the development of high blood pressure [7-9,26]. Besides, one has to consider the possible effect of long-standing high blood pressure. For example, subjects with currently normal blood pressure under medication might have had high blood pressure for a long time before it was recognized and treated. Therefore, it is necessary to evaluate the temporal sequence, acute and chronic effects and the causality between high blood pressure, its medical treatment and lung function in further prospective studies.

\section{Conclusions}

Our findings are in line with previous observations showing an inverse association between blood pressure and lung function. Furthermore, our analysis indicates that BBL medication and not any other antihypertensive treatment is associated with reduced lung function in a general adult population. Thus, our findings may serve as a basis for experimental testing, as for example by adding measurement of respiratory functions to outcomes of 'hypertensive' trials.

\section{Acknowledgements}

We thank all the participants in the study. We are indebted to the KORA study group which consists of H.-E. Wichmann (speaker), R. Holle, J. John, T. Illig, C. Meisinger, A. Peters and to all co-workers who are responsible for the design and conduct of the KORA studies.

Source of Funding

The KORA research platform (KORA, Cooperative Research in the Region of Augsburg) was initiated and financed by the Helmholtz Zentrum München, German Research Centre for Environmental Health, which is funded by the German Federal Ministry of Education, Science, Research and Technology and by the State of Bavaria.

The work was supported by the Competence Network Asthma/COPD funded by the Federal Ministry of Education and Research (FKZ 01GI0881-0888).

\section{Author details}

${ }^{1}$ Helmholtz Zentrum München, German Research Center for Environmental Health, Institute of Epidemiology, Neuherberg, Germany. ${ }^{2}$ LudwigMaximilians-University Munich, Dr. von Hauner Children's Hospital, Munich, Germany. ${ }^{3} \mathrm{Helmholtz}$ Zentrum München, Institute of Lung Biology and Disease, Munich, Germany. ${ }^{4}$ Ludwig-Maximilians-University Munich, Institute and Outpatient Clinic for Occupational, Social and Environmental Medicine, Munich, Germany. ${ }^{5}$ Comprehensive Pneumology Center, University Hospital of the Ludwig Maximilians University Munich, Asklepios Hospital Gauting and Helmholtz Zentrum München, Munich, Germany. ${ }^{6}$ Department of Internal Medicine B - Cardiology, Intensive Care, Pulmonary Medicine and Infectious Diseases, University of Greifswald, Greifswald, Germany. ${ }^{7}$ Central Hospital of Augsburg, MONICA/KORA Myocardial Infarction Registry, Augsburg, Germany. ${ }^{8}$ Ludwig-Maximilians-University, Institute of Medical Data Management, Biometrics and Epidemiology, Munich, Germany. ${ }^{9}$ Ludwig-Maximilians-University, Division of Pulmonary Diseases, Department of Internal Medicine I, Grosshadern, Munich, Germany. ${ }^{10}$ Ludwig-MaximiliansUniversity, Division of Respiratory Medicine, Department of Medicine, Innenstadt, Munich, Germany. "'Helmholtz Zentrum München, German Research Center for Environmental Health, Institute of Epidemiology II, Neuherberg, Germany.

\section{Authors' contributions}

ES was responsible for the data analysis, interpretation of data and manuscript preparation. JH and ES developed the statistical analysis plan. SK, $H S, S G, C M, M H, A P, H-E W, J B, R M H$ and JH assisted in the interpretation and critical revision of the results. SK, HS, CM, MH, H-EW and AP were

responsible for the data. All authors read and approved the final manuscript.

\section{Competing interests}

The authors declare that they have no competing interests.

Received: 15 December 2010 Accepted: 21 April 2011

Published: 21 April 2011

\section{References}

1. Kearney PM, Whelton M, Reynolds K, Whelton PK, He J: Worldwide prevalence of hypertension: a systematic review. J Hypertens 2004, 22(1):11-19.

2. Chobanian AV, Bakris GL, Black HR, Cushman WC, Green LA, Izzo JL Jr, Jones DW, Materson BJ, Oparil S, Wright JT Jr, Roccella EJ: Seventh report of the Joint National Committee on Prevention, Detection, Evaluation, and Treatment of High Blood Pressure. Hypertension 2003, 42(6):1206-1252.

3. Flack JM, Peters R, Shafi T, Alrefai H, Nasser SA, Crook E: Prevention of hypertension and its complications: theoretical basis and guidelines for treatment. J Am Soc Nephrol 2003, 14(7 Suppl 2):S92-S98.

4. Engstrom G, Hedblad B, Valind S, Janzon L: Increased incidence of myocardial infarction and stroke in hypertensive men with reduced lung function. J Hypertens 2001, 19(2):295-301.

5. Enright PL, Kronmal RA, Smith VE, Gardin JM, Schenker MB, Manolio TA: Reduced vital capacity in elderly persons with hypertension, coronary heart disease, or left ventricular hypertrophy. The Cardiovascular Health Study. Chest 1995, 107(1):28-35.

6. Margretardottir OB, Thorleifsson SJ, Gudmundsson G, Olafsson I, Benediktsdottir B, Janson C, Buist AS, Gislason T: Hypertension, systemic inflammation and body weight in relation to lung function impairmentan epidemiological study. COPD 2009, 6(4):250-255.

7. Selby JV, Friedman GD, Quesenberry CP Jr: Precursors of essential hypertension: pulmonary function, heart rate, uric acid, serum cholesterol, and other serum chemistries. Am J Epidemiol 1990, 131(6):1017-1027.

8. Sparrow D, Weiss ST, Vokonas PS, Cupples LA, Ekerdt DJ, Colton T: Forced vital capacity and the risk of hypertension. The Normative Aging Study. Am J Epidemiol 1988, 127(4):734-741.

9. Wu Y, Vollmer WM, Buist AS, Tsai R, Cen R, Wu X, Chen P, Li Y, Guo C, Mai J, Davis CE: Relationship between lung function and blood pressure in Chinese men and women of Beijing and Guangzhou. PRC-USA Cardiovascular and Cardiopulmonary Epidemiology Research Group. Int J Epidemiol 1998, 27(1):49-56. 
10. Doshan HD, Rosenthal RR, Brown R, Slutsky A, Applin WJ, Caruso FS: Celiprolol, atenolol and propranolol: a comparison of pulmonary effects in asthmatic patients. J Cardiovasc Pharmacol 1986, 8(Suppl 4):S105-S108.

11. Dransfield MT, Rowe SM, Johnson JE, Bailey WC, Gerald LB: Use of beta blockers and the risk of death in hospitalised patients with acute exacerbations of COPD. Thorax 2008, 63(4):301-305.

12. Mcneill RS: Effect of a beta-adrenergic-blocking agent, propranolol, on asthmatics. Lancet 1964, 2(7369):1101-1102.

13. Salpeter S, Ormiston T, Salpeter E: Cardioselective beta-blockers for reversible airway disease. Cochrane Database Syst Rev 2002, 1:CD002992.

14. Salpeter S, Ormiston T, Salpeter E: Cardioselective beta-blockers for chronic obstructive pulmonary disease. Cochrane Database Syst Rev 2005, 4:CD003566.

15. van Gestel YR, Hoeks SE, Sin DD, Welten GM, Schouten O, Witteveen HJ Simsek C, Stam H, Mertens FW, Bax JJ, van Domburg RT, Poldermans D: Impact of cardioselective beta-blockers on mortality in patients with chronic obstructive pulmonary disease and atherosclerosis. Am J Respir Crit Care Med 2008, 178(7):695-700.

16. van Zyl Al, Jennings AA, Bateman ED, Opie LH: Comparison of respiratory effects of two cardioselective beta-blockers, celiprolol and atenolol, in asthmatics with mild to moderate hypertension. Chest 1989, 95(1):209-213.

17. Nelson SB, Gardner RM, Crapo RO, Jensen RL: Performance evaluation of contemporary spirometers. Chest 1990, 97(2):288-297.

18. Quanjer PH, Tammeling GJ, Cotes JE, Pedersen OF, Peslin R, Yernault JC: Lung volumes and forced ventilatory flows. Report Working Party Standardization of Lung Function Tests, European Community for Steel and Coal. Official Statement of the European Respiratory Society. Eur Respir J Suppl 1993, 16(5-40)

19. Mühlberger N, Behrend C, Stark R: Datenbankgestützte Online-Erfassung von Arzneimitteln im Rahmen gesundheitswissenschaftlicher Studien Erfahrungen mit der IDOM-Software. Informatik Biometrie Epidemiologie Medizin Biologie 2003, 34(601-611).

20. Hochdruckliga Deutsche: Empfehlung zur Hochdruckbehandlung. 19 Auflage 2007.

21. Antonelli-Inc, Pedone C: Respiratory effects of beta-adrenergic receptor blockers. Curr Med Chem 2007, 14(10):1121-1128.

22. Martineau L, Horan MA, Rothwell NJ, Little RA: Salbutamol, a beta 2-adrenoceptor agonist, increases skeletal muscle strength in young men. Clin Sci (Lond) 1992, 83(5):615-621.

23. Angulo M, Taranto E, Soto JP, Malacrida L, Nin N, Hurtado FJ, Piriz H: Salbutamol improves diaphragmatic contractility in chronic airway obstruction. Arch Bronconeumol 2009, 45(5):230-234.

24. Grimm DR, Schilero GJ, Spungen AM, Bauman WA, Lesser M: Salmeterol improves pulmonary function in persons with tetraplegia. Lung 2006, 184(6):335-339.

25. Frankenstein L, Nelles M, Meyer FJ, Sigg C, Schellberg D, Remppis BA, Katus HA, Zugck C: Validity, prognostic value and optimal cutoff of respiratory muscle strength in patients with chronic heart failure changes with beta-blocker treatment. Eur I Cardiovasc Prev Rehabil 2009, 16(4):424-429.

26. Engstrom G, Wollmer P, Valind S, Hedblad B, Janzon L: Blood pressure increase between 55 and 68 years of age is inversely related to lung function: longitudinal results from the cohort study 'Men born in 1914'. $J$ Hypertens 2001, 19(7):1203-1208.

doi:10.1186/1465-9921-12-50

Cite this article as: Schnabel et al:: High blood pressure, antihypertensive medication and lung function in a general adult population. Respiratory Research 2011 12:50.

\section{Submit your next manuscript to BioMed Central and take full advantage of:}

- Convenient online submission

- Thorough peer review

- No space constraints or color figure charges

- Immediate publication on acceptance

- Inclusion in PubMed, CAS, Scopus and Google Scholar

- Research which is freely available for redistribution

Submit your manuscript at www.biomedcentral.com/submit
Biomed Central 